\title{
Treatment of myopic choroidal neovascularization with intravitreal ranibizumab injections: the role of age
}

This article was published in the following Dove Press journal:

Clinical Ophthalmology

22 June 2017

Number of times this article has been viewed

\author{
Dimitrios Karagiannis' \\ Georgios A Kontadakis ${ }^{1,2}$ \\ Konstantinos Kaprinis' \\ Athanassios Giarmoukakis ${ }^{2}$ \\ Ilias Georgalas ${ }^{3}$ \\ Efstratios A Parikakis \\ Miltiadis K Tsilimbaris ${ }^{2}$ \\ 'Ophthalmiatreio Eye Hospital of \\ Athens, Athens, Greece; ${ }^{2}$ Department \\ of Ophthalmology, University Hospital \\ of Heraklion, University of Crete, \\ Heraklio, Greece; ${ }^{3}$ Department of \\ Ophthalmology, University of Athens, \\ Athens, Greece
}

Purpose: The aim of this study was to explore the role of age as a prognostic factor for the outcome of myopic choroidal neovascularization (CNV) treatment with intravitreal ranibizumab injections.

Methods: A retrospective review of charts of patients treated with intravitreal injections of ranibizumab for the treatment of myopic $\mathrm{CNV}$ was done. Patients with other ophthalmic disease were excluded. Patients were followed for at least 2 years. The correlation between age and the change in visual acuity and the number of injections during treatment was investigated.

Results: Age of the patients was significantly correlated with the number of injections that the patients received (Pearson's $r=0.585, P=0.005$ ). Also, it was significantly correlated with improvement in corrected distance visual acuity, defined as the difference between final and initial LogMAR corrected distance visual acuity (Pearson's $r=0.614, P=0.003$ ).

Conclusion: Age significantly affects the visual outcome of myopic CNV treatment with ranibizumab. Younger patients in our study needed fewer intravitreal injections and achieved a more significant improvement in vision.

Keywords: myopic choroidal neovascularization, intravitreal injection, ranibizumab, pathologic myopia

\section{Introduction}

Myopia is a very common and usually benign ocular condition affecting a significant percentage of the adult population. ${ }^{1,2}$ Some of the affected patients however suffer from pathologic myopia which can be accompanied by vision-threatening complications. ${ }^{1,2}$ Definition of pathologic myopia included axial length and refraction in the past, but lately it has been refined as the eyes having chorioretinal atrophy equal to or more severe than diffuse atrophy. ${ }^{3,4}$ Within those eyes with pathologic myopia, $10.2 \%$ of the eyes may develop choroidal neovascularization (CNV). ${ }^{4}$ Myopic CNV is usually subfoveal or juxtafoveal and has small dimensions; it is located between the neurosensory retina and retinal pigment epithelium (classic CNV in fluorescein angiography) and is characterized by the presence of minimal subretinal fluid and hemorrhage. ${ }^{6,7}$ Myopic CNV accounts for almost $60 \%$ of CNV in patients $<50$ years of age. ${ }^{8}$ Visual prognosis of myopic CNV is generally poor, leading to severe visual impairment if left untreated. ${ }^{9}$

The standard treatment for myopic CNV has been photodynamic therapy (PDT) for many years. ${ }^{10}$ Visual outcomes of treatment with PDT were suboptimal though, leading to the implementation of additive treatments such as intravitreal triamcinolone.
Correspondence: Georgios A Kontadakis Ophthalmiatreio Eye Hospital of Athens, Eleftheriou Venizelou 26, GR 106 72, Athens, Greece

Email kontadas@yahoo.com (c) (7) (3) 2017 Karagiannis et al. This work is published and licensed by Dove Medical Press Limited. The full terms of this license are available at https://www.dovepress.com/terms.php (c) ${ }_{\mathrm{BY}} \mathrm{NC}$ and incorporate the Creative Commons Attribution - Non Commercial (unported, v3.0) License (http://creativecommons.org/licenses/by-nc/3.0/). By accessing the work you hereby accept the Terms. Non-commercial uses of the work are permitted without any further permission from Dove Medical Press Limited, provided the work is properly attributed. For permission for commercial use of this work, please see paragraphs 4.2 and 5 of our Terms (https://www.dovepress.com/terms.php). 
Lately, anti-VEGF agents with intravitreal injections have been adopted as first-line treatment, as their results for $\mathrm{CNV}$ in age-related macular degeneration have proven to be remarkable. ${ }^{11}$ Several studies of intravitreal anti-VEGF in myopic CNV have been conducted lately, demonstrating the superior visual and anatomical outcomes in comparison to PDT and other treatments. Both bevacizumab and ranibizumab have been used, with the latter being the only approved for intravitreal injection. Several factors have been associated with the outcome of treatment, such as visual acuity at onset and size of CNV. ${ }^{12,13}$

The purpose of our study was to identify and assess age as a prognostic factor for the outcome of treatment of myopic $\mathrm{CNV}$ with intravitreal ranibizumab injections.

\section{Methods}

This was a retrospective case series of patients with myopic $\mathrm{CNV}$ who received treatment with intravitreal ranibizumab injections in two centers, Ophthalmiatreio Eye Hospital of Athens and Ophthalmology Department of University Hospital of Heraklion. Institutional Review Board clearance was obtained from both centers. Patients were contacted, and all gave consent for inclusion in the study. We included all treatment-naïve patients who were diagnosed with myopic CNV and were then treated and followed for at least 2 years in those departments. All patients were diagnosed based on clinical presentation, fluorescein angiography, and spectral-domain optical coherence tomography (Spectralis, Heidelberg Engineering, Franklin, MA, USA). Diagnosis of pathologic myopia was confirmed by measurement of refractive error and axial length of patients. Treatment with ranibizumab intravitreal injections was initiated in all the reviewed patients. Patients who were lost to follow-up during treatment and patients who underwent ocular surgery or other ocular pathology treatment during follow-up were excluded from the study. Charts of all included patients were reviewed and the factors studied were the initial LogMAR corrected distance visual acuity (CDVA), the final CDVA, the number of injections given, and the age of the patients at initiation of treatment.

Treatment protocol was the same in all patients; specifically, we followed a monthly as per needed scheme, with an initial injection and then monthly follow-up and repeat injection until no signs of myopic CNV were evident on fluorescein angiography or no signs of hemorrhage were seen on funduscopy and CDVA was improved or stabilized. As a second line of examination, optical coherence tomography was also used, in order to detect the presence of subretinal fluid.

\section{Statistical analysis}

We assessed the correlation of age of the patients with the number of injections given and with the final improvement in CDVA. Also, we assessed the correlation of initial CDVA with the number of injections and the improvement of CDVA. As the limit of 40 years old was demonstrated in previous study ${ }^{14}$ to affect prognosis of myopic CNV, we divided our study group in two age subgroups ie, the younger age subgroup with patients aged less or equal to 40 years at presentation and the older subgroup with patients aged more than 40 years. We compared the visual outcome and the number of injections between the age subgroups.

\section{Results}

We included 21 patients in the study. In all cases, CNV was subfoveal. The average age of our patients was 53 years (range 22-86 years). All patients were Caucasians (Greek origin). Patient demographics are presented in Table 1. All patients were followed for at least 2 years. Patients in our study received intravitreal ranibizumab injection 1-12 times.

Age of the patients at presentation was significantly correlated with the number of injections the patients received (Pearson's $r=0.585, P=0.005$ ) (Figure 1). It was also significantly correlated with the improvement in CDVA, defined as the difference between final and initial LogMAR CDVA (Pearson's $r=0.614, P=0.003$ ) (Figure 2). Initial CDVA was not significantly correlated with age at presentation (Pearson's $r=0.207, P=0.368$ ), nor with the total number of injections (Pearson's $r=0.062, P=0.790$ ), but it was weakly correlated with improvement in CDVA (Pearson's $r=0.463, P=0.035$ ).

Regarding our subgroups, 7 patients were included in the younger group and 14 patients in the older group. The total number of injections was lower in the younger group, and the final CDVA and the improvement in CDVA were higher in the younger group. These differences were statistically significant (Table 2). Initial CDVA did not demonstrate

Table I Patient demographics and average values of study parameters

\begin{tabular}{|l|l|l|l|}
\hline$n$ & Males & \multirow{2}{*}{$2 \mathrm{I}$} & 3 \\
\cline { 4 - 4 } & Females & & 18 \\
\hline & Mean \pm SD & Range \\
\hline Age at presentation & $53 \pm 18.59$ & $22-86$ \\
\hline Number of injections & $5.7 I \pm 2.79$ & $\mathrm{I}-12$ \\
\hline Initial CDVA (LogMAR) & $0.55 \pm 0.23$ & $\mathrm{I}-0.18$ \\
\hline Final CDVA (LogMAR) & $0.44 \pm 0.30$ & $\mathrm{I} .09-0$ \\
\hline
\end{tabular}

Abbreviation: CDVA, corrected distance visual acuity. 


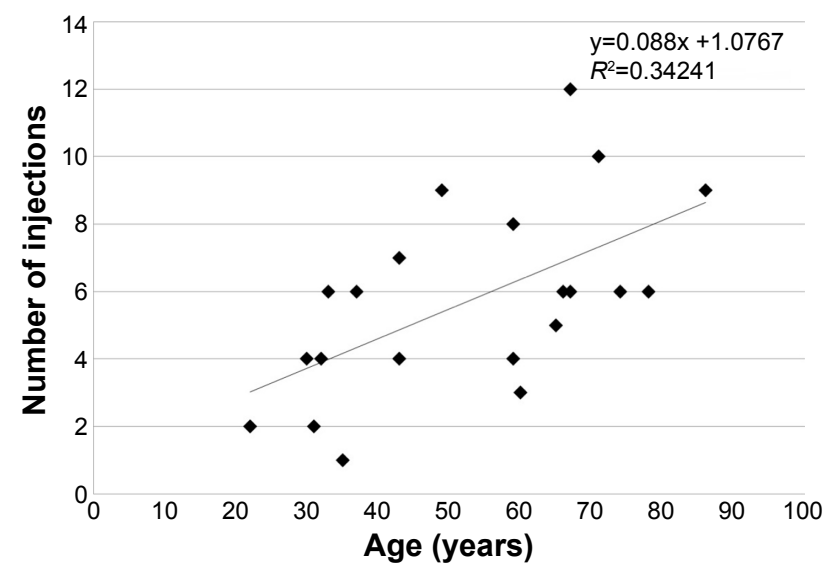

Figure I Scatter plot demonstrating the correlation between the number of injections received and the age of the patients.

a statistically significant difference among groups. All patients in the younger age group were stable or improved in comparison to the initial CDVA, versus only $57 \%$ of patients in the older age group $\left(P=0.04, \chi^{2}\right.$ test $)$. In the younger age group, $86 \%$ of patients had final CDVA equal to or better than $20 / 40$, while this was seen in only $14 \%$ of patients in the older age subgroup ( $P=0.001, \chi^{2}$ test).

\section{Discussion}

The visual prognosis of myopic CNV can be devastating, leading to severe visual impairment of affected individuals. In United States, it is estimated that up to $2 \%$ of the general population might be affected by pathologic myopia. Up to $11 \%$ of such patients might be affected by CNV.1,2,7 The natural history of this condition includes progressive and excessive elongation of the eyeball (posterior staphyloma), which may be accompanied by degenerative changes in the sclera, choroid, Bruch's membrane, retinal pigment

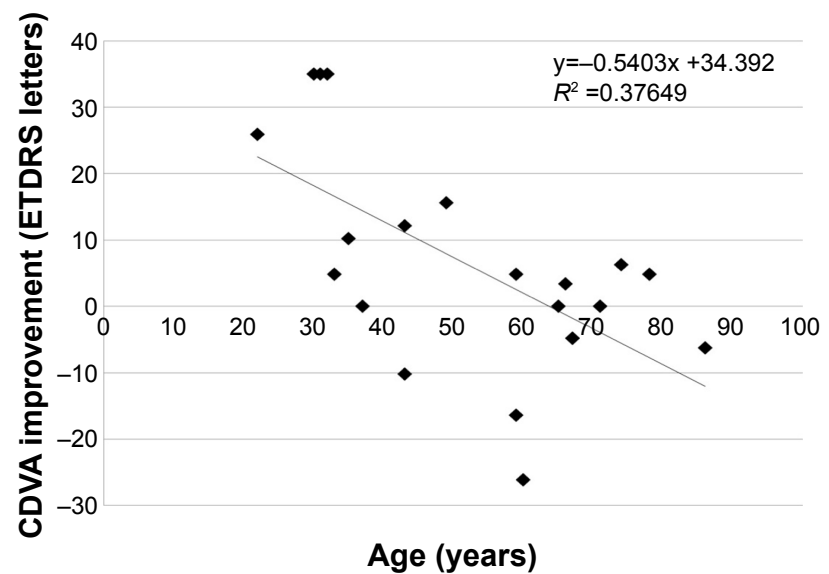

Figure 2 Scatter plot demonstrating the correlation between improvement in CDVA after treatment and the age of patients.

Abbreviations: CDVA, corrected distance visual acuity; ETDRS, early treatment of diabetic retinopathy study. epithelium, and neurosensory retina. Areas of retinal pigment epithelium atrophy and lacquer cracks in Bruch's membrane and choroid may develop due to progressive and excessive elongation of the anteroposterior axis, which causes a mechanical stress on the retina, leading to an imbalance between proangiogenic and antiangiogenic factors, resulting in myopic CNV. ${ }^{3-5}$ According to a 10 year follow-up study, in the long-term, $22 \%$ of the eyes that present with subretinal bleeding will regress, and chorioretinal atrophy developed in $96.3 \%$ of patients at 5 years. Almost all of the patients dropped to 20/200 or less CDVA after 5-10 years from the onset of CNV. ${ }^{9}$

Age has a significant role in the prognosis of myopic $\mathrm{CNV}$ even if left untreated. In a previous retrospective case series ${ }_{14}^{14}$ patients with myopic CNV were divided in two groups, similarly to our study, by using 40 years of age as a limit. In this study, the final visual acuity was better in the younger age group, and the percentage of patients with improved or stable visual acuity was higher in the younger age group as well (27\% and 54\%, respectively, in the below 40 years old group versus $17 \%$ and $32 \%$, respectively, in the above 40 years old group). Additionally, fewer patients in the younger group developed chorioretinal atrophy. This study indicated age as a significant factor for the visual prognosis of the disease when left untreated. ${ }^{14}$

Our study demonstrated that age is a significant factor that also affects the result of treatment with intravitreal ranibizumab in such eyes. According to our study, patients treated when they were $<40$ years old showed improved vision or remained stable, and this was in contrast to patients $>40$ years of age, where $57 \%$ of the patients only were stable or showed improved outcome. Also, the final visual outcome was different between groups, with significantly more patients reaching final vision better than 20/40 in the young group than in the old group. Patients and physicians need to be aware of the different visual prognosis among age groups.

Other prognostic factors for anti-VEGF treatment that have been identified in the literature are the patients' visual acuity at baseline, the lacquer crack extension to the fovea, the peripapillary atrophy, and the CNV size. ${ }^{12,13}$ In a study of bevacizumab injections, prognostic factors associated with better visual outcomes were the lower rate of development of chorioretinal atrophy, smaller pretreatment CNV size, and younger age. ${ }^{12}$ Age has also been correlated with better outcomes for PDT of myopic CNV. ${ }^{10}$ In our study, we investigated only the age as a factor and demonstrated that it is a significant independent prognostic factor for visual outcome of treatment with ranibizumab injections. 
Table 2 Comparison of study parameters between the younger and the older age groups

\begin{tabular}{|c|c|c|c|}
\hline Age, years & $\leq 40$ & $>40$ & $P$-value \\
\hline $\mathbf{N}$ & 7 & 14 & \\
\hline Number of injections & $\begin{array}{l}3.57 \pm 1.99 \\
1-6\end{array}$ & $\begin{array}{l}6.79 \pm 2.55 \\
3-12\end{array}$ & 0.007 (Mann-Whitney $U$ test) \\
\hline Initial CDVA (LogMAR) & $\begin{array}{l}0.62 \pm 0.23 \\
0.3-1\end{array}$ & $\begin{array}{l}0.52 \pm 0.23 \\
0.18-1\end{array}$ & 0.4 (Mann-Whitney $U$ test) \\
\hline Final CDVA (LogMAR) & $\begin{array}{l}0.20 \pm 0.19 \\
0-0.52\end{array}$ & $\begin{array}{l}0.55 \pm 0.28 \\
0.15-1.09\end{array}$ & 0.004 (Mann-Whitney $U$ test) \\
\hline $\begin{array}{l}\text { Improvement in CDVA (ETDRS } \\
\text { letters) }\end{array}$ & $\begin{array}{l}20.83 \pm 15.42 \\
0-35\end{array}$ & $\begin{array}{l}-1.55 \pm 11.08 \\
-26-15\end{array}$ & 0.006 (Mann-Whitney $U$ test) \\
\hline $\begin{array}{l}\text { Stable or improved } \\
(n, \%)\end{array}$ & $7(100 \%)$ & $8(57 \%)$ & $0.04\left(\chi^{2}\right.$ test $)$ \\
\hline
\end{tabular}

Notes: Data presented as mean $\pm S D$, range. Bold data are statistically significant.

Abbreviations: CDVA, corrected distance visual acuity; ETDRS, early treatment of diabetic retinopathy study.

In addition to visual outcome, the need for retreatments was also affected by age in our study. Significantly less retreatment was needed in younger patients in our as-perneeded scheme for the targeted outcome of improvement and/or stabilization. A previous study demonstrated that the CNV size and the duration of symptoms were significant prognostic factors for the number of injections, but age was not included in the predictors. ${ }^{13}$ According to our results, the number of intravitreal injections needed to reach the target of treatment is correlated with age of the patients.

\section{Conclusion}

Consequently, our study demonstrates that age significantly affects the visual outcome of myopic CNV treatment with ranibizumab and the need for retreatments, and this is similar to how it affects the natural history of the disease if left untreated. To our knowledge, this is the first study demonstrating the significance of age in the prognosis of ranibizumab treatment. According to our results, the outcome might be significantly different in patients of younger age, and they also need significantly lesser intravitreal injections.

\section{Disclosure}

The authors report no conflicts of interest in this work.

\section{References}

1. Wong TY, Ferreira A, Hughes R, Carter G, Mitchell P. Epidemiology and disease burden of pathologic myopia and myopic choroidal neovascularization: an evidence-based systematic review. Am J Ophthalmol. 2014;157:9.e12-25.e12.

2. Wong TY, Ohno-Matsui K, Leveziel N, et al. Myopic choroidal neovascularisation: current concepts and update on clinical management. British J Ophthalmol. 2015;99:289-296.
3. Ohno-Matsui K, Lai TY, Lai CC, Cheung CM. Updates of pathologic myopia. Prog Retin Eye Res. 2016;52:156-187.

4. Ohno-Matsui K, Kawasaki R, Jonas JB; META-analysis for Pathologic Myopia (META-PM) Study Group. International photographic classification and grading system for myopic maculopathy. Am J Ophthalmol. 2015;159:877.e7-883.e7.

5. Ohno-Matsui K, Yoshida T, Futagami S, et al. Patchy atrophy and lacquer cracks predispose to the development of choroidal neovascularisation in pathological myopia. Br J Ophthalmol. 2003;87:570-573.

6. Iacono P, Battaglia Parodi M, Papayannis A, et al. Fluorescein angiography and spectral-domain optical coherence tomography for monitoring anti-VEGF therapy in myopic choroidal neovascularization. Ophthalmic Res. 2014;52:25-31.

7. Chan NS, Teo K, Cheung CM. Epidemiology and diagnosis of myopic choroidal neovascularization in Asia. Eye Contact Lens. 2016; 42:48-55.

8. Cohen SY, Laroche A, Leguen Y, Soubrane G, Coscas GJ. Etiology of choroidal neovascularization in young patients. Ophthalmology. 1996; 103:1241-1244

9. Yoshida T, Ohno-Matsui K, Yasuzumi K, et al. Myopic choroidal neovascularization: a 10-year follow-up. Ophthalmology. 2003;110: 1297-1305.

10. Axer-Siegel R, Ehrlich R, Weinberger D. Photodynamic therapy of subfoveal choroidal neovascularization in high myopia in a clinical setting: visual outcome in relation to age at treatment. Am JOphthalmol. 2004;138:602-607.

11. Munk MR, Rückert R, Zinkernagel M, Ebneter A, Wolf S. The role of anti-VEGF agents in myopic choroidal neovascularization: current standards and future outlook. Expert Opin Biol Ther. 2016;12:1-11.

12. Yang HS, Kim JG, Kim JT, Joe SG. Prognostic factors of eyes with naïve subfoveal myopic choroidal neovascularization after intravitreal bevacizumab. Am J Ophthalmol. 2013;156:1201.e12-1210.e2.

13. Ng DS, Kwok AK, Tong JM, Chan CW, Li WW. Factors influencing need for retreatment and long-term visual outcome after intravitreal bevacizumab for myopic choroidal neovascularization. Retina. 2015; 35:2457-2468.

14. Yoshida T, Ohno-Matsui K, Ohtake Y, et al. Long-term visual prognosis of choroidal neovascularization in high myopia: a comparison between age groups. Ophthalmology. 2002;109:712-719. 
Clinical Ophthalmology

\section{Publish your work in this journal}

Clinical Ophthalmology is an international, peer-reviewed journal covering all subspecialties within ophthalmology. Key topics include: Optometry; Visual science; Pharmacology and drug therapy in eye diseases; Basic Sciences; Primary and Secondary eye care; Patien Safety and Quality of Care Improvements. This journal is indexed on

Submit your manuscript here: http://www.dovepress.com/clinical-ophthalmology-journal

PubMed Central and CAS, and is the official journal of The Society of Clinical Ophthalmology (SCO). The manuscript management system is completely online and includes a very quick and fair peer-review system, which is all easy to use. Visit http://www.dovepress.com/ testimonials.php to read real quotes from published authors. 